\title{
Asymptomatic papillary fibroelastoma of the aortic valve
}

\author{
M. Hordijk-Trion, G. Bol-Raap, M.J.M. Kofflard
}

A previously healthy 63-year-old woman with multiple risk factors for coronary artery disease was referred to the outpatient clinic with a three-month history of atypical chest pain. At physical examination no abnormalities could be detected and the ECG was completely normal. At transthoracic echocardiography and transoesophageal echocardiography a mass, $1 \mathrm{~cm}$ in diameter and attached to the right coronary cusp of the aortic valve, was detected. The mass had the echocardiographic appearance of a nonhomogeneous, round, dense, mobile structure, typical features of a fibroelastoma (figure 1). On dipyridamole-thallium scintigraphy, no coronary insufficiency could be demonstrated. Since cardiac papillary fibroelastomas are associated with a risk of thromboembolic events, the patient underwent complete tumour excision by a simple shave excision (figure 2). Histopathological evaluation indeed revealed the mass to be a papillary fibroelastoma. The patient's recovery was uneventful.

Papillary fibroelastoma is the most frequent primary cardiac valvular tumour, but its true incidence is unknown. Fibroelastomas may cause cerebrovascular events, angina, myocardial infarction and sudden cardiac death as a result of distal embolisation. Embolisation is generally caused by fibrin strands or thrombus formation, which are released from the surface of the

\section{Hordijk-Trion}

\section{M.J.M. Kofflard}

Department of Cardiology, Albert Schweitzer Hospital,

Dordrecht, the Netherlands

\section{G. Bol-Raap}

Department of Cardiothoracic Surgery, Thoraxcenter, Erasmus MC, Rotterdam, the Netherlands

Correspondence to: M.J.M. Kofflard

Department of Cardiology, Albert Schweitzer Hospital, location Dordwijk, PO Box 444, 3300 AK Dordrecht, the Netherlands E-mail: m.j.m.kofflard@asz.nl

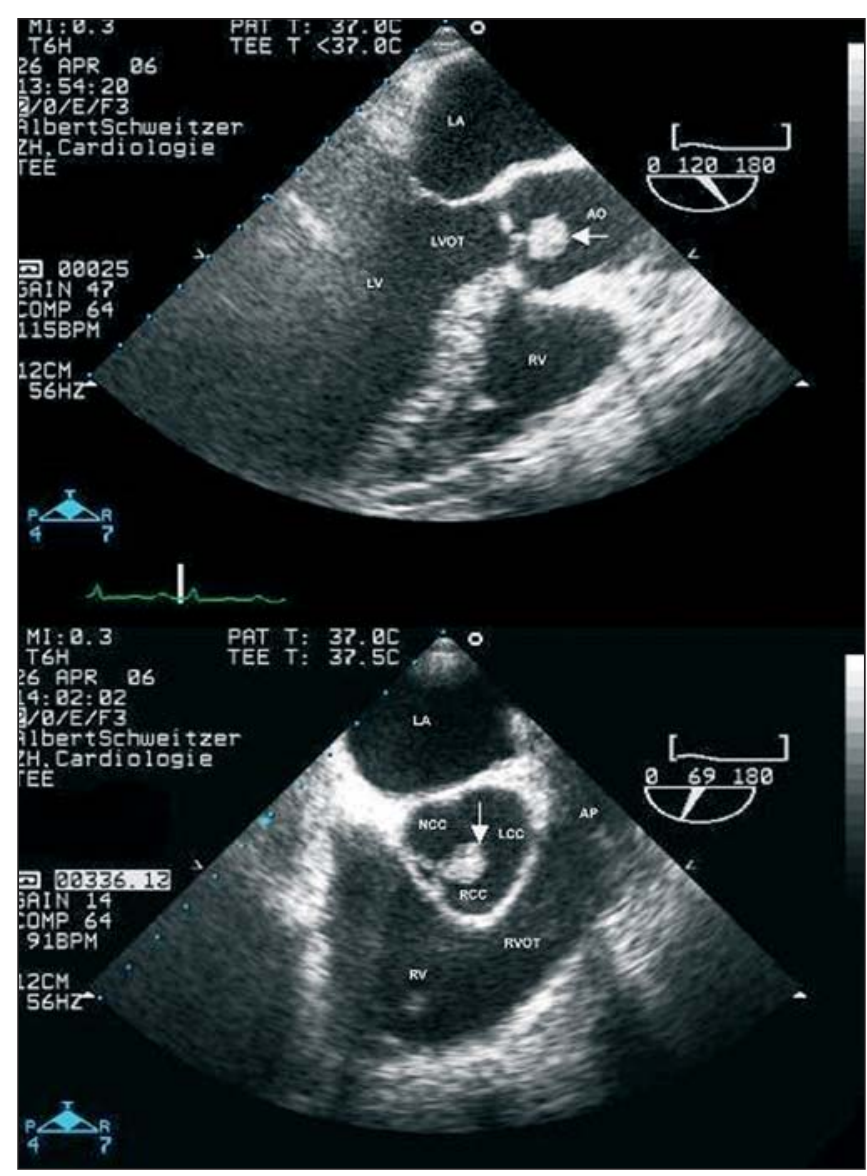

Figure 1. Above: Transoesophageal long-axis view at $120^{\circ}$, demonstrating a mass attached to the right coronary cusp (RCC) of the aortic valve. Below: Transoesophageal short-axis view at $69^{\circ}$, demonstrating a mass attached to the right coronary cusp (RCC) of the aortic valve. The arrow points to the mass. $L A=l$ eft atrium, $L V=l e f t$ ventricle, LVOT=left ventricular outflow tract, $A o=$ ascending aorta, $R V=$ right ventricle, $R V O T=$ right ventricular outflow tract, $A P=$ pulmonary artery, NCC=noncoronary cusp of the aortic valve, LCC=left coronary cusp of the artic valve. 


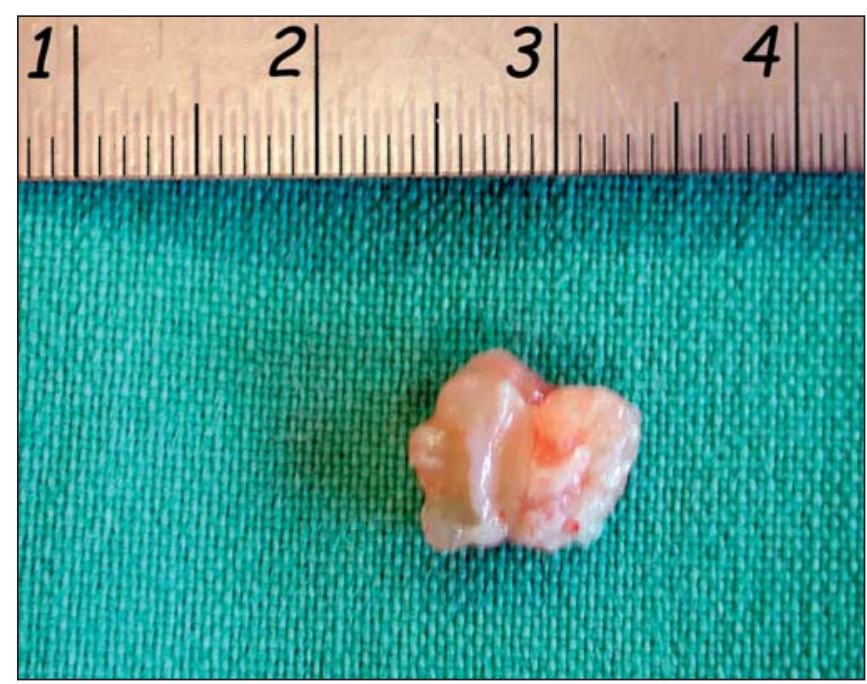

Figure 2. Macroscopic appearance and size of the mass after surgical excision.

tumour. ${ }^{1}$ A fibroelastoma is usually diagnosed by echocardiography: often a solitary tumour, $<1 \mathrm{~cm}$ diameter, attached to the mid portion of valve leaflets, often pedunculated with high-frequency oscillations during the cardiac cycle, and a characteristic frond-like or sea anemone appearance. ${ }^{2}$ Surgical resection is warranted because of potentially serious neurological complications. ${ }^{3}$ Surgery by simple shave excision is a safe, effective and valve-sparing technique with good long-term results reducing the need for postoperative anticoagulation. ${ }^{3}$ Oral anticoagulation can be offered to patients who are not candidates for surgery due to their clinical condition. ${ }^{4}$

\section{References}

I Sun JP, Asher CR, Yang XS, Cheng GG, Scalia GM, Massed AG, et al. Clinical and echocardiographic characteristics of papillary fibroelastomas: a retrospective and prospective study in 162 patients. Circulation 2001;103:2687-93.

2 Klarich KW, Enriquez-Sarano M, Gura GM, Edwards WD, Tajik AJ, Seward JB. Papillary fibroelastoma: echocardiographic characteristics for diagnosis and pathologic correlation. J Am Coll Cardiol 1997;30:784-90.

3 Ngaage DL, Mullany CJ, Daly RC, Dearani JA, Edwards WD, Tazelaar HD, et al. Surgical treatment of cardiac papillary fibroelastoma: a single center experience with eighty-eight patients. Ann Thorac Surg 2005;80:1712-8

4 Gowda RM, Khan IA, Nair CK, Mehta NJ, Vasavada BC, Sacchi TJ. Cardiac papillary fibroelastoma: A comprehensive analysis of 725 cases. Am Heart J 2003;146:404-10.

In this section a remarkable 'image' is presented and a short comment is given.

We invite you to send in images (in triplicate) with a short comment (one page at the most) to Bohn Stafleu van Loghum, PO Box 246, 3990 GA Houten, e-mail: 1.jagers@bsl.nl.

'Moving images' are also welcomed and (after acceptance) will be published as a Web Site Feature and shown on our website: www.cardiologie.nl

This section is edited by M.J.M. Cramer and J.J. Bax. 